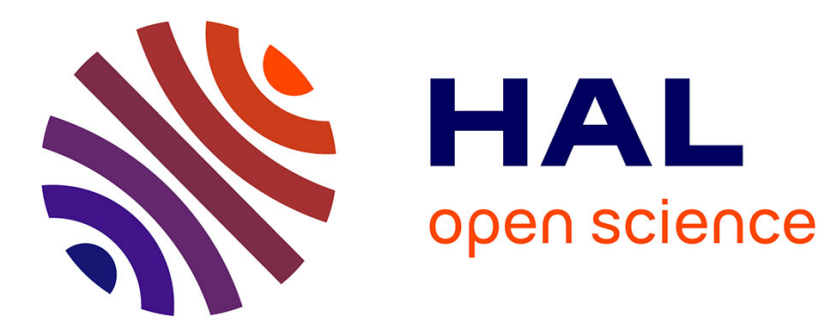

\title{
Comparative pessimism or optimism: Depressed mood, risk-taking, social utility and desirability
}

Isabelle Milhabet, Emmanuelle Lebarbenchon, Laurent Cambon, Guylaine Molina

\section{- To cite this version:}

Isabelle Milhabet, Emmanuelle Lebarbenchon, Laurent Cambon, Guylaine Molina. Comparative pessimism or optimism: Depressed mood, risk-taking, social utility and desirability. Spanish Journal of Psychology, 2015, 18 (E10), 10.1017/sjp.2015.9 . hal-01421038

\section{HAL Id: hal-01421038 \\ https://hal-amu.archives-ouvertes.fr/hal-01421038}

Submitted on 3 Jan 2017

HAL is a multi-disciplinary open access archive for the deposit and dissemination of scientific research documents, whether they are published or not. The documents may come from teaching and research institutions in France or abroad, or from public or private research centers.
L'archive ouverte pluridisciplinaire HAL, est destinée au dépôt et à la diffusion de documents scientifiques de niveau recherche, publiés ou non, émanant des établissements d'enseignement et de recherche français ou étrangers, des laboratoires publics ou privés. 


\title{
Comparative Pessimism or Optimism : Depressed Mood, Risk-Taking, social utility and desirability
}

Isabelle Milhabet ${ }^{1}$, Emmanuelle Le Barbenchon ${ }^{2}$, Laurent Cambon ${ }^{1}$ and Guylaine Molina ${ }^{3}$

\author{
${ }^{1}$ Université Nice-Sophia Antipolis (France) \\ ${ }^{2}$ Université de Savoie Laurent Cambon (France) \\ ${ }^{3}$ Aix-Marseille Université, EA4671 ADEF, ENS de Lyon (France)
}

Correspondence concerning this article should be addressed to Isabelle Milhabet. Laboratoire d'Anthropologie et de Psychologie Cognitives et Sociales. Université de NiceSophia Antipolis. Pôle Universitaire Saint-Jean d'Angély. 24, Av. des Diables bleus. 06357. Nice Cedex 4. E-mail: milhabet@unice.fr 


\begin{abstract}
Comparative optimism can be defined as a self-serving, asymmetric judgment of the future. It is often thought to be beneficial and socially accepted, whereas comparative pessimism is correlated with depression and socially rejected. Our goal was to examine the social acceptance of comparative optimism and the social rejection of comparative pessimism in two dimensions of social judgment, social desirability and social utility, considering the attributions of dysphoria and risk-taking potential (studies 2 and 3) on outlooks on the future. In three experiments, the participants assessed either one (study 1) or several (studies 2 and 3) fictional targets in two dimensions, social utility and social desirability. Targets exhibiting comparatively optimistic or pessimistic outlooks on the future were presented as nondepressed, depressed, or neither (control condition) (study 1); non-depressed or depressed (study 2); and non-depressed or in control condition (study 3). Two significant results were obtained: 1) social rejection of comparative pessimism in the social desirability dimension, which can be explained by its depressive feature, and 2) comparative optimism was socially accepted on the social utility dimension, which can be explained by the perception that comparatively optimistic individuals are potential risk-takers.
\end{abstract}

Keywords: comparative optimism and pessimism; utility and desirability; social rejection and acceptance; depressed mood; risk-taking 
When people consider their futures and those of others, they may comparatively display either optimism or pessimism. Comparative optimism (CO) refers to considering one's own future in a better light than others' futures (Weinstein, 1980). Conversely, comparative pessimism (CP) is a tendency that consists of considering one's own future in a worse light than those of others.

A number of studies have shown that expressing $\mathrm{CO}$ or $\mathrm{CP}$ has important consequences for social acceptance; most often, people are valued when they display CO but socially rejected when they display CP (Carver, Kus, \& Scheier, 1994; Helweg-Larsen, Sadeghian, \& Webb, 2002; Vollmann, Renner, \& Weber, 2007).

However, most of these studies compared the social acceptance of comparative optimism and comparative pessimism. The social acceptance of a comparatively optimistic outlook has not been found to differ from that of a neutral outlook; and there was no obvious evidence of greater social acceptance of comparative optimism but there was rather a tendency for social rejection of comparative pessimism per se. Moreover, the examination of the social acceptance of $\mathrm{CO}$ compared to $\mathrm{CP}$ was conducted in a kind of social vacuum. However, we know that the valuation of an object is often affected by the context in which it appears (Helson, 1964; Mussweiler, 2003). Then, the main objective of the present paper was to examine the social acceptance or rejection of both $\mathrm{CO}$ and $\mathrm{CP}$ per se in different dimensions of social judgment to better understand the consequences of exhibiting $\mathrm{CO}$ or $\mathrm{CP}$, as well as the causes of rejection and acceptance.

\section{Outlook on the future, social acceptance and social judgment dimensions}

Many studies have demonstrated that there are two dimensions of social judgment. These dimensions have been given a variety of names but it is worth noting that no major empirical differences have been demonstrated between these various conceptualizations (Wojciszke \& Abele, 2008). In this study, we have used the distinction between social 
desirability and social utility (Dubois \& Beauvois, 2005): (a) for purposes of comparison with previous results about social acceptance of comparative optimism obtained in the literature (Le Barbenchon \& Milhabet, 2005; Le Barbenchon, Milhabet, Steiner, \& Priolo, 2008; Milhabet, Le Barbenchon, Molina, Cambon, \& Steiner, 2012); (b) because this conceptualization is explicitly linked to evaluative judgment which is the focus of our attention in this paper. Indeed, in the literature, the analogs to social desirability and social utility such as communion and agency or warmth and competence are based on a psychological realism assumption. Thus, in this conception, the two dimensions are assumed to be two realities existing in a descriptive (quasi-scientific) psychology, and psychological descriptions are considered as real descriptions of peoples' personalities. For the evaluative approach (Dubois \& Beauvois, 2011), the two dimensions are seen as two aspects of the social value of people and the psychological descriptions are considered as direct expressions of persons' social value. This last assumption is supported by generally strong correlations between descriptions with personality traits on the two dimensions and evaluative statements related to these two dimensions (Cambon, Djouary, \& Beauvois, 2006).

"Social desirability" refers to the types of affects that individuals elicit from others, or the manners in which individuals satisfy other people's principal motivations. Accordingly, social desirability informs us of the "likeableness" we can attribute to others in their relationships with others. The social acceptance measured in the friendship domain is obviously related to the social desirability dimension. By contrast, "social utility" refers to an individual's chance of success or failure in her/his social life and is based on how well she/he meets the requirements of the society in which she/he live. In this approach, social utility has a quasi-economic connotation, rather than a functional one. In other words, an individual's social utility refers to her/his "market" value and not to the services that she/he might perform for a particular individual or group in a specific context. For example, the value of leadership 
behaviors relates to the social utility dimension; a leader is an individual who is successful in her/his social life and useful for an organization.

Based on this distinction, Le Barbenchon and Milhabet (2005) have shown that displays of CO may be simultaneously socially accepted in one of these dimensions and socially rejected in the other. Le Barbenchon et al. (2008) showed that displays of CO are more socially accepted in the social utility dimension than in the social desirability dimension. In the latter dimension, $\mathrm{CO}$ targets are poorly accepted and occasionally rejected. These conclusions are supported by the results of other studies; results have shown, for example, that 1) displays of CO may be perceived as signs of overconfidence and pretentiousness in the friendship domain (Taylor, Lerner, Sherman, Sage, \& McDowell, 2003) and 2) there may be a correlation between displays of CO and advantageous selfdescription for leaders (Dolbier, Soderstron, \& Steinhardt, 2001; Hickman, Watson, \& Morris, 1996; House \& Shamir, 1998). These results indicate that the social acceptance of CO is not unanimous. Furthermore, $\mathrm{CO}$ was expected to be more socially accepted in the social utility dimension and less socially accepted in the social desirability dimension compared with a neutral outlook on the future (Hypothesis 1a).

The above distinction between the two social judgment dimensions demonstrates that examining the social acceptance of different outlooks on the future within the two dimensions is particularly relevant. Presently, these dimensions have only been used to explore the social acceptance of CO and not the social rejection of CP. Helweg-Larsen et al. (2002) observed that displays of CP are generally socially rejected (compared with neutral or optimistic outlooks), regardless of the judgment dimension. CP is then expected to be rejected in both social judgment dimensions, compared to a neutral outlook (Hypothesis 1b).

If these authors show interesting new results which give a social dimension to the judgments of the perception of the future, they do not present their reasons. Then, the second 
aim was to understand the major process that underlies social judgments concerning $\mathrm{CP}$ and CO. In the literature, two major processes are proposed to explain these social judgments: 1) comparatively pessimistic individuals are rejected because they are associated with stigmatized traits, such as displaying nonclinical depressed mood (or dysphoria), and 2) comparatively optimistic individuals are accepted because they display risk-taking potential (Helweg-Larsen et al., 2002).

\section{Outlook on the future, social rejection and mood}

In experiment 2, Helweg-Larsen et al. (2002) demonstrated that the depressed mood attributed to the $\mathrm{CP}$ targets explained their social rejection. The authors manipulated the information regarding the targets' outlooks on the future (CP vs. neutral vs. $\mathrm{CO}$ ). In addition, they either presented the targets as being in excellent mental health (i.e., "not depressed or hopeless, and [...] in a good mood most of the times", p. 99) or withheld this information (i.e., standard condition). When the targets were presented without any information, the displays of CP were considered less socially acceptable than the neutral outlooks, which were no less socially accepted than the displays of CO. The targets were all socially accepted when presented as being in good mental health. In other words, the CP targets may have been socially rejected because they were perceived as being in a depressed mood. Such an assumption raises three concerns.

First, the role of depressed mood has been reported regardless of the social judgment dimension. Social rejection based on excessive reassurance seeking (which is associated with depression) has been observed by roommates, best friends and dating partners (Starr \& Davila, 2008). In other words, depressed (Starr \& Davila, 2008) and dysphoric individuals (Siegel \& Alloy, 1990) are rejected, but these results apply only in the social desirability dimension. The hypothesis of the social rejection of depressed and CP individuals in the social utility dimension has not been examined. 
Second, the mood attributed to the target does not impact the social judgments about CO targets (Helweg-Larsen et al., 2002). The social rejection of CO that has been observed in the social desirability dimension may have different causes than the social rejection of CP.

Third, outlook on the future and depression may or may not co-occur (Alloy \& Ahrens, 1987; Pietromonaco \& Markus, 1985; Pyszczynski \& Greenberg, 1986, 1987). One can intuitively suppose that people display $\mathrm{CP}$ when they are depressed, and this is often observed (Alloy \& Ahrens, 1987). In such cases, seeking excessive reassurance targets are socially rejected on both dimensions of social judgment (Helweg-Larsen \& al., 2002; Starr \& Davila, 2008). Some authors have shown that some depressed individuals display CO (Pietromonaco \& Markus, 1985; Pyszczynski \& Greenberg, 1985). This intuitive incongruence, manipulated by Helweg-Larsen et al. (2002), is possible because one can exhibit one's outlook on the future as a manner of coping or as a strategy of self-presentation (Tyler \& Rosier, 2009; Taylor \& Brown, 1988). Many authors have argued that comparative optimism refers to positive illusions that have positive psychological benefits for depressed individuals (Armor \& Taylor, 1998; Shepperd, Grace, Cole, \& Klein, 2005). These benefits could also concern the social acceptance of $\mathrm{CO}$ in depressed individuals (Chambers \& Windschitl, 2004; Tyler \& Rosier, 2009). Conversely, a non-depressed individual could display CP as a modest self-presentation strategy or as a self-handicap (i.e., modest target). Modesty as a self-presentation strategy is particularly effective for social acceptance in friendship relations and in the social desirability dimension (Tice, Butler, Muraven, \& Stillwell, 1995). It is then possible to conceive that someone can be non-depressed but display CP. Finally, more frequently, non-depressed individuals display CO. These "narcissistic targets" are socially accepted on the dimension of social utility but rejected on the dimension of social desirability (Le Barbenchon \& Milhabet, 2005; Le Barbenchon et al., 2008; Milhabet et al., 2012). 
Based on these concerns, the hypothesis addresses only the dimension of social desirability because no results are available concerning the social judgment of dysphoria in the social utility dimension. It is hypothesized that dysphoria attributed to the $\mathrm{CO}$ targets reduces their social rejection (Hypothesis 2a); positive illusion targets (i.e., depressed CO targets) are expected to be less socially rejected in the social desirability dimension than narcissistic targets (i.e., non-depressed CO targets). Concerning CP displays, it is expected that dysphoria attributed to the CP targets increases their social rejection (Hypothesis $2 \mathrm{~b}$ ); excessive reassurance seeking (i.e., in depressed CP targets) is expected to be more socially rejected in the social desirability dimension than a modest target (i.e., non-depressed CP targets).

\section{Outlook on the future, social acceptance and risk-taking potential}

The role of risk-taking potential in the target is used to explain the social acceptance of CO (Helweg-Larsen et al., 2002). The link between risk and optimism has often been studied in economics (Bougheas, 2002; Ucbasaran, Westhead, Wright, \& Flores, 2010), sociology (Peretti-Watel, 2005; Spire \& Peretti-Watel, 2008) and psychology (Quadrel, Fischhoff, \& Davis, 1993; van der Velde, van der Pligt, \& Hooykaas, 1994; Weinstein, Marcus, \& Moser, 2005). However, few studies have examined the relationship between risk-taking and the acceptance of comparative optimism. Helweg-Larsen et al. (2002) observed that optimistic targets are the most socially accepted and are perceived as taking the most risks. The authors concluded that perceived risk-taking is not regarded as a negative attribute (Zuckerman, 1979, 1990). This conclusion is consistent with other studies. For example, Anderson and Galinsky (2006) assumed that optimism is associated with risky choices in professional domains, which may lead to superior performance. This explanation fits particularly well with the social acceptance of CO in the social utility dimension (Le Barbenchon \& Milhabet, 2005; Le Barbenchon et al., 2008; Milhabet et al., 2012). CO may be beneficial in the professional 
domain because it is perceived as leading to firm value maximization (Anderson \& Galinsky, 2006) and investment in new economic markets (Bougheas, 2002). It is predicted that regardless of the experimental condition (depressed or non-depressed), the $\mathrm{CO}$ targets are perceived as taking appropriate risks which may explain that $\mathrm{CO}$ targets are thus socially accepted in the social utility dimension; while the $\mathrm{CP}$ targets are perceived as taking less risks (Hypothesis 3). This hypothesis was tested in studies 2 and 3.

\section{Study 1}

\section{Method}

\section{Participants and experimental design}

Two hundred and three participants ranging from 18 to 67 years old $(M=31.59 ; S D=$ 13.35) were recruited from the street and at a train station to participate in this experiment (109 women and 94 men). The participants agreed to participate in the study ${ }^{1}$, which they were told concerned personality and perception of the future. A 3 (Target's Depressive Status: depressed vs. non-depressed vs. control) x 3 (Targets' Outlooks on the Future: CP vs. neutral vs. CO) between-participants experimental design was used, with 21 to 25 participants in each group. In all studies, the participants were each randomly assigned to one the experimental conditions. They read the information and answered the questions concerning the target. After the experiment, the participants were debriefed and thanked for their participation.

\section{Dependent variables}

Three dependent variables were tested: 1) the social acceptance of the target on the desirability and utility dimensions, 2) the target's ratings of the personality trait adjectives, and 3) the dysphoria attributed to the target (on specific adjectives).

\section{Materials}

\footnotetext{
${ }^{1}$ The participants were volunteered and received no form of compensation (in all studies).
} 
First, the mental health presentation of the target was manipulated (depressed or not). In experimental conditions (depressed or not), the target's depressive character was specified three times: once, verbally, by experimenter, at the beginning of the instructions ("After reading description about an individual not depressed, not sad, not dysphoric and in good psychological health, and..." versus "After reading description about an individual depressed, sad, dysphoric and in bad psychological health, and..."); a second time, it was written, on the first page of the booklet used to in the study (see details below); and a third time it was underlined on the second page of the booklet where there was the entire target-portrait. In the control condition, no information about depressed or not was provided.

Second, the target's outlook on the future was manipulated as either CP, neutral or $\mathrm{CO}$. The participants were informed that the target had answered a questionnaire concerning their outlook on their own future and that of another average individual of similar age and sex. The participants were told (and they also read) that the target's scores on the questionnaire were comparatively optimistic, comparatively pessimistic or neither. In addition, to be more concrete, the participants were given two examples. For example, a comparatively optimistic target said that they were more likely to "attend a happy event" and "get a good job soon after graduating" than another person of similar age and sex. This classic manipulation of the targets' outlooks on the future (CP vs. neutral vs. $\mathrm{CO}$ ) was enhanced by a quantitative score that was given to participants. The participants were informed that the target had answered a questionnaire on a percentage scale. An average fictitious percentage for the target was indicated to the participants. In the neutral condition, the target's and other individual's percentages were similar, with no difference in outlooks. The neutral target had a percentage of $0 \%$, whereas the CP and CO targets had percentages of $-34 \%$ and $+34 \%$, respectively. A score of $-34 \%$ meant that, on average, the target expressed $34 \%$ more pessimism than the other individual. The converse was true for the optimistic comparative 
target $(+34 \%)$. These percentages were the same as those of the study Milhabet et al. (2012). Beyond $62 \%$, the targets were seen as less credible.

There were nine target profiles: 3 (Target's Depressive Status: not depressed vs. depressed vs. none) x 3 (Target's Outlook: CP vs. Neutral vs. CO). All of the conditions were crossed. However, some profiles might seem less possible than others. For this reason, at the end of the questionnaire, two questions related to the plausibility (i.e., "to what extent do you think this person's answers regarding their future are plausible?") and consistency (i.e., "to what extent do you think this person's answers regarding their future seem consistent?”) of the targets (on a 7-point scale) were included. All of the targets were observed to be similarly plausible and consistent $(M=4.38 ; S D=1.51), F(4,194)=1.68, n s$. However, one target, the depressed and comparatively optimistic one, was judged to be less plausible than the others $(M=3.96 ; S D=1.42)$. Despite this low mean, we kept these targets in the final experimental material.

Judgment of social acceptance.

Each participant answered ten questions regarding one of nine different targets (see Appendix 1). Five questions corresponded to social acceptance in the social desirability dimension (Cronbach's alpha $(\alpha)>.78$ in studies 1 and 3), and five corresponded to social acceptance in the social utility dimension $(\alpha>.87$ in studies 1 and 3). The answers were provided on scales ranging from 1 (not at all) to 7 (entirely). The participants' mean responses were calculated for each dimension of social judgment. The judgments of social desirability were correlated with the judgments of social utility $(r=.58, p<.01$ in study $1 ; r=.67, p<.01$ in study 3$)$. When the correlation between $\mathrm{X}$ and $\mathrm{Y}$ is equal to, or approaching the reliability of $\mathrm{X}$ or $\mathrm{Y}$, then $\mathrm{X}$ and $\mathrm{Y}$ are considered the same construct (Nunnally \& Bernstein, 1994). So, we also set up the $95 \%$ confidence intervals (CIs) around the correlation of .58 (study 1) and 
.67 (study 3 ). The $95 \%$ CIs ranged from .51 to .65 in study 1 , and from .59 to .75 in study 3 , and thus clearly excluded the $\alpha$ s (in study 1 , the two $\alpha$ s were .78 and .87 , in study 3 , they were .85 and .92). This led us to regard the two constructs as psychometrically distinct but the two dimensions are not necessarily orthogonal. Target ratings on the personality traits (desirability and utility).

The participants rated the targets using 12 personality traits (see appendix 2) ranging from 1 (not at all) to 7 (entirely) (Cambon, 2006) obtained from the crossing of the two dimensions of social desirability and social utility and of positive and negative valence $(.70 \geq \alpha \mathrm{s} \leq .81)$.

The participants' mean target ratings were calculated for each dimension of the personality trait adjectives (the mean ratings of the positive desirability traits minus the mean ratings of the negative desirability traits, and the mean ratings of the positive utility traits minus the mean ratings of the negative utility traits). This is how each target's ratings were obtained, including one of desirability traits and one of social utility traits; each ranged from -6 (not at all) to +6 (entirely). The ratings of the desirability traits were correlated with the ratings of the utility traits $(r=.32, p<.01$ in study $1 ; r=.27, p<.01$ in study 2 ). The ratings of the traits were also correlated with means of social acceptance $(r=.40, p<.01$ for desirability; $r=.55, p<.01$ for utility). Dysphoria attributed to the targets.

The participants rated the targets in terms of four mood adjectives on a scale ranging from 1 to 7: very happy - very sad, definitely not depressed - definitely depressed, definitely not hopeless - definitely hopeless, and definitely funny definitely not funny. These four questions, all of which were based on the same construct (target's dysphoria), were computed in a single index ( $\alpha>.85$ in all studies). The greater the score, the more dysphoric the target was perceived to be. 


\section{Targets' outlooks for the future.}

We asked the participants to rate the targets' outlooks for the future (i.e., "how do you think this individual sees his/her future?") on a scale ranging from 1 (pessimistic) to 7 (optimistic). The $\mathrm{CP}$ targets $(M=2.55 ; S D=1.32)$ were judged as more pessimistic than the targets in the control condition $(M=4.09 ; S D=1.10)$; these targets were judged as less optimistic than the CO targets $(M=4.92 ; S D=1.64), F(2$, $\left.194)=51.04, p<.0001, \eta^{2}=.05\right)$. In all of the studies, the results confirmed that our experimental manipulations were successful.

\section{Results $^{2}$}

\section{Dysphoria attributed to the targets}

The expected main effect of target's depressive status, $F(2,194)=14.87, p<.001$; $\eta^{2}=.01$, showed that targets were judged more dysphoric when presented as being depressed $(M=4.52 ; S D=1.07)$ than in the control condition $(M=3.78 ; S D=1.21)$ or as nondepressed $(M=3.68 ; S D=1.01)$. Furthermore, a main effect of target's outlook on the future, $F(2,194)=30.94, p<.0001, \eta^{2}=.02$, indicated that the CP targets $(M=4.74 ; S D=.88)$ were judged to be more dysphoric than both the neutral targets $(M=3.81 ; S D=.89), F(1,194)=$ 29.60, $p<.0001)$, and the $\mathrm{CO}$ targets $(M=3.49 ; S D=1.27), F(1,194)=4.30, p<.05$. Thus, the CP targets were presumed to have high levels of dysphoria.

\section{Mean social judgments of the targets' social acceptance}

Only the significant effects and the effects related to the hypotheses are described in this section. The CP targets $(M=3.16 ; S D=0.92)$ were judged less favorably than the neutral $(M=3.89 ; S D=1.24)$ and $C O$ targets $(M=4.04 ; S D=1.08), F(2,194)=742.14, p<.0001$; however, the neutral and CO targets did not significantly differ, $F(1,194)=.82$, ns. Overall,

\footnotetext{
${ }^{2}$ In all studies, analyzes of variance were computed based on hypotheses and were supplemented by planned comparisons
} 
the targets were judged more favorably in the desirability dimension $(M=3.83 ; S D=1.09)$ than in the utility dimension $(M=3.56 ; S D=1.16), F(1,194)=15.80, p<.0001, \eta^{2}=.01$.

The interaction between outlook and the dimensions of social judgment was significant, $F(2,194)=11.39, p<.0001, \eta^{2}=.01$ (Table 1$)$. Hypothesis 1a expected that the $\mathrm{CO}$ targets are more accepted than the neutral targets in the social utility dimension; however, this effect was not observed in the social desirability dimension. Compared to the neutral targets, the CP targets were generally rejected in both dimensions, as predicted in Hypothesis $1 b$; however, they were less rejected in the desirability dimension than in the social utility dimension.

Table 1

There was a significant interaction between target presentation, target outlook and the social judgment dimensions, $F(4,194)=2.51, p<.05, \eta^{2}=.0002$ (Hypothesis 2 ; Table 2). However, the depressed CP target (i.e., the excessively reassurance-seeking target) was not observed to be less rejected than the non-depressed CP target (i.e., the modest target; Hypothesis $2 \mathrm{~b}$ ), and the depressed CO target (i.e., the positive illusion target) was less rejected than the non-depressed $\mathrm{CO}$ target (i.e., the narcissistic target; Hypothesis $2 \mathrm{a}$ ).

Table 2

An ANCOVA was conducted to examine the control condition and the influence of dysphoria attributed to the targets on social acceptance (i.e., dependent variable). To test perceived dysphoria's effect on social judgments and to avoid results that could be explained by the experimental manipulation, this analysis only examined the control condition. Target outlook (CP vs. Neutral vs. CO) was the between-participants factor (i.e., independent variable), the social judgment dimension (social desirability vs. social utility) was the withinparticipants factor (i.e., independent variable), and the dysphoria attributed to the target was the covariate. When the dysphoria attributed to the target was constant, the $\mathrm{CP}$ targets were no 
more socially rejected than the neutral targets in either the social desirability or the social utility dimensions, $F(1,66)<1$, ns. Similarly, when the perceived dysphoria was constant, the $\mathrm{CO}$ targets were no more socially rejected than the neutral targets in the social desirability dimension, $F(1,66)<1, n s$; however, the $\mathrm{CO}$ targets tended to be more accepted in the social utility dimension than the neutral targets, $F(1,66)=3.26, p=.074$.

\section{Mean ratings on the personality trait adjectives}

The ANOVA revealed significant main effects from target outlook, $F(2,194)=5.23$, $p<.01, \eta^{2}=.02$, and personality trait dimension, $F(1,194)=10.73, p<.01, \eta^{2}=.01$. However, the most notable result was the significant effect of the interaction between target outlook and personality trait dimension, $F(2,194)=27.97, p<.0001, \eta^{2}=.05$ (Table 3$)$. The $\mathrm{CO}$ targets were given higher ratings for the social utility traits and lower ratings for the social desirability traits than the neutral targets, $F(1,194)=8.72, p<.01$ and $F(1,194)=$ $11.04, p<.01$ (respectively), which was expected (Hypothesis 1a). Consistent with Hypothesis $1 \mathrm{~b}$, the CP targets were rejected in the social utility dimension $(M=2.27 ; S D=.99)$ compared to the neutral targets, $F(1,194)=11.29, p<.01$, and they also tended to be rejected in the social desirability dimension $(M=4.24 ; S D=1.05), F(1,194)=2.97, p=.08$. Altogether, these results supported Hypothesis $1 \mathrm{~b}$, although the social rejection of the CP targets was more salient in the social utility dimension than in the social desirability dimension.

Table 3

None of these effects interacted with the targets' presentations in terms of depression, $F(4,194)<1, n s$, which indicated that compared to the neutral targets, social judgments concerning the $\mathrm{CP}$ and $\mathrm{CO}$ targets were similar, regardless of whether they were presented as depressed or non-depressed (Hypothesis 2).

To investigate the effect of the perceived depressive status of the target on the personality trait ratings of that target, a second ANCOVA was conducted in the control 
condition, using the dysphoria attributed to the target as a covariate (for the same reasons mentioned above). The results showed that when the perceived dysphoria was constant, the $\mathrm{CP}$ targets were no more socially rejected based on personality traits than the neutral targets in either dimension, $F(1,66)<1, n s$. However, the $\mathrm{CO}$ targets remained more positively rated in social utility, $F(1,66)=4.84, p<.05$, and more negatively rated in social desirability than the neutral targets, $F(1,66)=4.43, p<.05$.

\section{Discussion}

First, the results showed that $\mathrm{CO}$ is socially accepted in the social utility dimension but socially rejected in the social desirability dimension, in comparison to a neutral outlook on the future (Hypothesis 1a), as observed by Le Barbenchon and Milhabet (2005). Moreover, these results showed, for the first time that $\mathrm{CP}$ is socially rejected, compared with a neutral outlook, in the two social judgment dimensions (Hypothesis 1b). The social judgments of targets displaying $\mathrm{CP}$ or $\mathrm{CO}$ were here compared with the social judgment of targets displaying neutral comparative outlook on the future. It is interesting to note that the neutral targets were manipulated to be neither optimistic nor pessimistic. They are neutral for their expression of the future. Yet, these neutral outlooks on the future are more socially accepted on the dimension of desirability than on the dimension of utility. Milhabet et al. (2012; experiments 1-3) showed the same results because to be perceived useful and more useful than desirable, the $\mathrm{CO}$ must be expressed unambiguously. Thus, unsurprisingly, the neutral target is perceived as more desirable and useful. Moreover, the positivity of the neutral target on social desirability probably relates to the person positivity bias which refers to a behavioral approach tendency in the participants (Peeters, 1971). The fact that this bias appeared only on the desirability scales is also consistent with the fact that these scales, more than the social utility ones, are more related to the approach-avoidance tendency (Peeters, 2002). Otherwise, these neutral targets may generate affects because they did not display explicit social 
comparison (Mussweiler, 2003). We mentioned above that the neutral target did not displayed comparative outlook on the future. The social judgment of $\mathrm{CP}$ and $\mathrm{CO}$ could then result from the social comparison displayed by $\mathrm{CP}$ and $\mathrm{CO}$. A way to deal with this issue is to compare the social judgments of targets with different levels of CO or CP. For this reason, we added several degrees of comparative pessimism and optimism in the second study. The expected differences in the first study between neutral and $\mathrm{CP}$ or $\mathrm{CO}$ targets are now expected between the different degrees of comparative outlooks on the future (Hypotheses 1).

More specifically, concerning the social rejection of CP targets, it can be explained by the dysphoria perceived in $\mathrm{CP}$ individuals. Two results support this assumption: 1) the $\mathrm{CP}$ targets were spontaneously perceived to be more dysphoric than the neutral and CO targets, and 2) the CP targets were no longer socially rejected when the dysphoria attributed to the targets was constant. Therefore, these results extend those of Helweg-Larsen et al.'s (2002) study considering the two dimensions of social judgment. However, unlike hypothesis $2 b$, the CP targets were not more socially rejected when they were presented as depressed (i.e., excessively reassurance-seeking) than when they were presented as non-depressed (i.e., modest). Although the manipulation of the target presentation was effective (the depressed targets were judged to be more dysphoric than the neutral and non-depressed targets), the expected effect did not occur. In a second study, re-examination of these results was proposed, this time maintaining the most problematic and radical conditions (i.e., depressed or non-depressed).

This first study also showed other new results. The social rejection of perceived dysphoria in two social dimensions was tested, and it was observed that a depressed mood is socially rejected in the dimensions of both social desirability (Starr \& Davila, 2008) and, for the first time, social utility. The results of this study show that perceived dysphoria explains the social rejection of $\mathrm{CP}$ and the partial rejection of $\mathrm{CO}$. However, we are aware of the fact 
that the results of the ANCOVA should be interpreted with caution, because the inclusion of covariates which were measured after the manipulation of the independent variable can lead to problematic interpretations. For this reason, we conducted a second study with an experimental design giving us the possibility to directly test the influence of perceived dysphoria for social judgments.

The present study shows that depressed targets are socially rejected when they are perceived as excessively reassurance-seeking but not when they display $\mathrm{CO}$ as a positive illusion. These results confirm that displaying $\mathrm{CO}$ as a positive illusion has positive social consequences for depressed individuals (Chambers \& Windchitl, 2004; Taylor \& Brown 1988). It also seems that $\mathrm{CP}$ is no more rejected than $\mathrm{CO}$ in the social desirability dimension when the target displays CP as a modest self-presentation strategy (among non-depressed targets). We replicated Study 1 by considering the main limitations of this study.

\section{Study 2}

\section{Method}

\section{Participants and experimental design}

The participants were 171 students (145 women and 26 men) ranging from 18 to 39 years old $(M=19.65 ; S D=3.12)$. The participants agreed to participate in an experiment investigating personality and perceptions of the future. A 2 (Target's Depressive Status: nondepressed vs. depressed) x 5 (Target's Outlook on the Future: high CP vs. CP vs. neutral vs. $\mathrm{CO}$ vs. high $\mathrm{CO}$ ) experimental design was used. The first independent variable was a between-participants factor, while the second was a within-participants factor. Five profiles were presented in five random orders. The experimental procedure was the same than in the first study.

\section{Dependent variables}


Three dependent variables were tested: 1) ratings of the targets on the personality trait adjectives, 2) the dysphoria attributed to the targets, and 3) the risk-taking potential attributed to the targets.

\section{Materials}

The material used was a 15-page booklet. Three pages were assigned to each target. The first half-page contained a description of the target. The target's description presented the target in terms of both independent variables: their level of depression and their outlook on the future. This description was intended to allow a target to be, for example, simultaneously depressed and comparatively optimistic. Each target was explicitly described as either depressive or non-depressive: half of the participants were informed that the targets were sad, were depressed, and had specific problems, whereas the remaining participants were informed that the targets were not sad, were not depressed, and had no particular problems (i.e., nondepressed). After this information was provided, it was explicitly stated that the target was either very strongly $\mathrm{CP}, \mathrm{CP}$, neutral, $\mathrm{CO}$, or very strongly $\mathrm{CO}$. This half-page was followed by a series of questions organized into blocks (or tables). Each block of questions corresponded to one of the dependent variables and additional measures. The items were identical to those in the first study. Four items were created $(\alpha>.85$ in studies 2 and 3$)$ to assess the risk-taking potential attributed to the target (i.e., "do you think that this person could take risks to get a job with a high social status?").

The preliminary results showed the effectiveness of the manipulation. A significant effect from target presentation (non-depressed vs. depressed) on the judgment of depression was observed, $F(1,672)=9.05, p<.0001, \eta^{2}=.01$. The CP targets were judged as pessimistic, and the $\mathrm{CO}$ targets were judged as optimistic, $F(4,672)=552.28, p<.0001$, $\eta^{2}=.16$. The credibility of the targets was also examined. All of the targets were observed to be similarly plausible, $F(4,194)=1.68, n s$. However, two of the targets were judged to be 
weaker than the rest: the depressive target and optimistic $(M=3.68 ; S D=1.83)$ and highly optimistic targets $(M=3.64 ; S D=1.84), F(4,672)=10.90, p<.0001$. All targets were retained.

\section{Results}

\section{Dysphoria attributed to the targets}

Consistent with the manipulation, it was observed that the perceived dysphoria was influenced by the target presentation, $F(1,169)=104.27, p<.0001, \eta^{2}=.01$ : when participants were informed that the target was depressed, they judged that the target was highly dysphoric $(M=3.56 ; S D=1.65)$, but not when they were informed that the target was non-depressed $(M=4.40 ; S D=1.40)$, as expected. We observed a main effect of target outlook, $F(4,676)=364.70, p<.0001, \eta^{2}=.08$; the most comparative optimistic targets were judged as the least dysphoric, $F(1,169)=808.19, p<.01$ (linear contrast).

\section{Mean ratings of risk-taking potential}

An ANOVA revealed a significant interaction between the two independent variables, $F(4,676)=6.00, p<.001, \eta^{2}=.0005$, which indicated that the $\mathrm{CO}$ targets were perceived to have greater risk-taking potential than the neutral targets, whether the targets were portrayed as depressed or non-depressed (Table 4). However, the CP targets were perceived as potentially taking fewer risks than the neutral targets, and this effect was stronger when the CP targets were depicted as depressed.

Table 4

\section{Mean ratings of personality trait adjectives}

The statistical design of this dependent variable was a 2 (Target's Depressive Status: non-depressed vs. depressed) x 5 (Target's Outlook on the Future: highly CP vs. CP vs. neutral vs. CO vs. highly CO) x 2 (Valence Adjective: positive vs. negative) x 2 (Adjectives' Social Dimension: desirable vs. useful) design. The first independent variable was a between- 
participants factor, and the other independent variable a within-participants factors. To make these results easier to follow, the meaningful significant interaction between the four independent variables is described in some detail, $F(4,676)=3.76, p<.005, \eta^{2}=.00009$ (Figure 1). Highly CO targets were rated as more useful, $F(1,169)=11.01, p<.01$, and more undesirable, $F(1,169)=23.34, p<.001$, than the CO targets, as expected (Hypothesis 1a). In accordance with hypothesis $1 \mathrm{~b}$, the highly $\mathrm{CP}$ targets were rated as less desirable, $F(1,169)=$ $10.54, p<.01$, and less useful, $F(1,169)=28.37, p<.001$, than the CP targets. In all cases, the targets were regarded as less useful than desirable in the trait adjectives, $F(1,169)=$ $24.89, p<.001, \eta^{2}=.0004$.

\section{Figure 1}

The CO targets were less rejected in the social desirability dimension when they were depressed (positive illusion targets) than when they were non-depressed (narcissistic targets), $F(1,169)=4.55, p<.05$, as expected (Hypothesis $2 \mathrm{a})$. Contrary to hypothesis $2 \mathrm{~b}$, the depressed $\mathrm{CP}$ targets (excessively reassurance-seeking targets) were rated as more desirable than the non-depressed CP targets (modest targets), $F(1,169)=9.73, p<.01$.

The influences of dysphoria and risk-taking potential on mean ratings of personality traits (useful and desirable)

Finally, to understand the influences of perceived risk-taking potential and dysphoria on each dimension, multiple regressions were conducted for the $\mathrm{CP}$ and $\mathrm{CO}$ targets (nonneutral targets). Dysphoria and risk-taking potential perceived in the target were used as predictors of the mean ratings of personality traits (Table 5).

Table 5

It was observed that the role of dysphoria perceived in the target differed as a function of the target's outlook on the future and as a function of the social judgment dimension. In the dimension of social desirability, depressed mood reduced the social rejection of the CP 
targets. In the dimension of social utility, perceived dysphoria increased the social rejection of the $\mathrm{CO}$ targets. Finally, it was observed that the risk-taking potential attributed to the $\mathrm{CO}$ targets was unrelated with their personality trait ratings which did not support our hypothesis 3.

\section{Discussion}

In this second study, the results supported those previously noted (i.e., the first study). In short, $\mathrm{CO}$ was socially accepted in the social utility dimension but not in terms of social desirability and CP was generally rejected.

Moreover, study 2 investigated the reasons behind the social acceptance of the CO targets and the social rejection of the CP targets. The results revealed that a target who was judged to be dysphoric was actually socially rejected in the social utility dimension.

Concerning hypothesis 2 , it was observed that the CO target was less rejected in the social desirability dimension when it was presented as having a depressed mood (i.e., the positive illusion targets), compared to the non-depressed CO target (i.e., the narcissistic target). Thus, the depressed mood of the $\mathrm{CO}$ target reduced its social rejection in the social desirability dimension, as hypothesized (2a). Similar effects were observed for the CP targets; the CP targets were less rejected when they were depressed (i.e., the excessively reassurance-seeking targets) than when they were non-depressed (i.e., the modest targets). This effect was not expected, but it is consistent with the notable results: dysphoric targets who disconfirmed the expectations of the participant (i.e., the target was non-depressed, whereas the participant expected a depressed target) were socially rejected (Alloy, Fedderly, Kennedy-Moore, \& Cohan, 1998). However, experimental manipulation may have stimulated the participants from a confirmation perspective. Another explanation for this unexpected effect could be that the participants counterbalanced the social rejections of CP and depressed mood in the social utility dimension and moderated the social rejection of $\mathrm{CP}$ and depressed mood in the social 
desirability dimension. Furthermore this effect may have been an experimental artifact; in fact, the participants who socially rejected the CP targets could justify their social judgment with the unique information that was provided to them concerning the depressed status of the target. Thus, it was important to test, in a third study, whether participants would reject the CP targets because they spontaneously attributed a depressed mood to CP.

Finally, we tested the hypothesis that individuals were judged as socially useful when they were considered likely to take appropriate risks (Hypothesis 3). The results showed that the useful targets were also judged to have a risk-taking potential. However, their risk-taking potential seemed unrelated to their social value when the effect of dysphoria was controlled for (see multiple regressions). The experimental manipulation (i.e., the induction of the target's mood) may have artificially enhanced the role of depressed mood and increased its salience beyond the role of risk-taking potential in social judgments. A third study was conducted to examine these different aspects.

\section{Study 3}

In study 3 , a single control condition and a single non-depressed condition were implemented, as in the study of Helweg-Larsen et al. (2002). The control condition would allow investigation of the influences of spontaneous attributions of depressed mood and risktaking potential on social acceptance and rejection. This third study provides new analyses to better understand the influences of mood and risk-taking in the rejection and acceptance of pessimism and optimism. The aim was to investigate the social acceptance of $\mathrm{CP}$ and $\mathrm{CO}$ in the two dimensions of social judgment while considering dysphoria and risk-taking as mediating variables.

\section{Method}

\section{Participants and experimental design}


Forty psychology students (33 women and 7 men; $\mathrm{M}_{\mathrm{age}}=19.2 ; S D=2.1$ ) volunteered to participate in an experiment about judgment of individuals. A 2 (Target's Depressive Status: control vs. non-depressed) x 9 (Target's Outlook: CP4 vs. CP3 vs. CP2 vs. CP1 vs. N vs. $\mathrm{CO} 1$ vs. $\mathrm{CO} 2$ vs. $\mathrm{CO} 3$ vs. $\mathrm{CO} 4)$ experimental design was implemented. The first independent variable was a between-participants factor, and the second was a withinparticipants factor. There were 20 participants in the control group and 20 in the nondepressed group, as in study 1 . The experimental procedure was the same than the one used in the previous studies.

\section{Materials and Dependent variables}

The material used was a 20-page booklet. The initial two pages of the booklet contained the instructions. The participants were presented with nine targets and their responses to a questionnaire concerning outlook on the future, as in study 1 . The nine targets were introduced simultaneously on page 3 , followed by detailed descriptions of the individual targets. In the following pages, three sets of questions were provided, addressing 1) the targets' social acceptance in the social desirability and utility dimensions, 2) the dysphoria attributed to the targets and 3) the ratings of risk-taking potential (three items, $\alpha=.75$ ). These three sets of questions were tested as three dependent variables.

The presentation of the targets.

First, the presentations of the targets were manipulated. Half of the participants were informed that the targets were not sad or depressed and had no particular problems (like in previous studies). The remaining participants were not informed about the targets' depressive statuses (the control condition). Second, the targets' levels of $\mathrm{CO}$ and $\mathrm{CP}$ were manipulated using percentage scales (for details, see study 1). The levels of $\mathrm{CP}$ were indicated by negative percentages $(\mathrm{CP} 4=-68 \%, \mathrm{CP} 3=-$ $51 \%, \mathrm{CP} 2=-34 \%, \mathrm{CP} 1=-17 \%)$, whereas the levels of CO were indicated by positive 
percentages $(\mathrm{CO} 1=+17 \%, \mathrm{CO} 2=+34 \%, \mathrm{CO} 3=+51 \%, \mathrm{CO} 4=+68 \%)$. There was also a neutral level (+/-0\%). Additionally, the participants received explanations about $\mathrm{CO}, \mathrm{CP}$, neutrality, and the percentages of each. These preliminary results confirmed the effectiveness of the manipulation, $F(8,304)=108.65, p<.0001, \eta^{2}=.15$.

\section{Results}

\section{Dysphoria attributed to the targets}

The target presentation (control vs. non-depressed) had no effect on perceived dysphoria, $F(1,38)=0.62, n s$, indicating that the manipulation was not effective. An ANOVA revealed a main effect from target outlook, $F(8,304)=70.09, p<.001, \eta^{2}=.06$ (Table 6). In accordance with the previous results, the CP targets were judged to be dysphoric (i.e., sad, depressed, not hopeless and not funny), and the CO targets were perceived to be non-dysphoric.

Table 6

\section{Mean target ratings of risk-taking potential}

The results showed that the higher the targets' levels of $\mathrm{CP}$, the lower the ratings of their risk-taking potential, $F(1,38)=19.31, p<.001$ (linear contrast). Additionally, the higher the targets' $\mathrm{CO}$ levels, the higher the ratings of their risk-taking potential, $F(1,38)=10.58, p$ $<.001$, as expected (Hypothesis 3) (Table 7).

Table 7

\section{Mean judgments of the targets' social acceptance}

The CO targets were socially accepted in the social utility dimension, $F(1,38)=$ $36.81, p<.001$ (linear contrast), but not in the social desirability dimension, $F(1,38)=.79$, ns (linear contrast). Additionally, the $\mathrm{CP}$ targets were socially rejected; the higher their $\mathrm{CP}$ levels, the greater their rejection in the social desirability, $F(1,38)=53.36, p<.001$, and social utility dimensions, $F(1,38)=84.54, p<.001$ (linear contrast). It is noteworthy that the 
$\mathrm{CP}$ targets were less rejected in terms of desirability than in terms of social utility; these results supported Hypothesis $1 \mathrm{~b}$ (Table 8).

Table 8

\section{The influences of perceived dysphoria and risk-taking potential on social acceptance}

Given that the experimental manipulation (i.e., target's depressive status) did not have any effect on the dysphoria attributed to the targets, a multiple mediation analysis was conducted to investigate the influences of perceived dysphoria and risk-taking potential in the targets on the mean social judgments (for details of the method, see Preacher \& Hayes, 2008). Only data from the control condition were used; the data did not include the neutral targets. Four multiple mediation analyses were performed for the $\mathrm{CP}$ and $\mathrm{CO}$ targets in the social desirability and social utility dimensions. For each analysis, the independent variable was the target's outlook, the mediators were the mean ratings of perceived dysphoria and risk-taking potential, and the dependent variable was the mean judgment of social desirability (or social utility). The mean judgment in the social utility (or in the social desirability) dimension was a covariate (Figure 2). All variables were standardized. The bootstrap results were interpreted (with a sample of 5000), as recommended by Preacher and Hayes (2008) (Table 9).

Figure 2

Table 9

The rejection of the $\mathrm{CO}$ targets in the social desirability dimension was explained neither by perceived dysphoria (Hypothesis 2a) nor by perceived risk-taking potential. However, their acceptance in the social utility dimension was partially mediated by their risktaking potential. In other words, the higher the $\mathrm{CO}$ levels of the participants, the higher the ratings of their risk-taking potential and the greater their acceptance in the social utility dimension. Their non-depressed moods did not account for their acceptance in the social utility dimension (Hypothesis 3). 
For the $\mathrm{CP}$ targets, the results showed that the dysphoria spontaneously attributed to them by the participants entirely mediated their social rejection in the social desirability dimension. In other words, the higher the targets' CP levels, the more dysphoric they were perceived to be, which then caused them to be rejected in the social desirability dimension (Hypothesis 2b). When the effect of perceived dysphoria was controlled for, the targets ceased to be socially rejected because of their CP. An identical analysis showed that the risktaking potential attributed to the $\mathrm{CP}$ targets was not related to their rejection in the social desirability dimension. In the social utility dimension, the results showed that neither perceived dysphoria nor perceived risk-taking potential was implicated in the rejection of the targets. In other words, the social rejection of the CP targets in the social utility dimension was not explained by perceptions of dysphoria or weak risk-taking potential.

\section{Discussion}

First, in this third study, the results supported those obtained in studies 1 and 2; the social judgments of $\mathrm{CP}$ and $\mathrm{CO}$ differed as a function of dimension (social desirability vs. social utility). Second, the results confirmed that when the participants had no information regarding the target's depressive status, the CP targets were rejected in the social desirability dimension because they were perceived to be dysphoric. In other words, the stigma of depression biased the judgments. Being comparatively pessimistic is harmful enough that individuals are socially rejected for the purposes of future friendships (but not necessarily for the sake of future professional relations). Third, the results confirmed that one of the reasons for the social acceptance of $\mathrm{CO}$ in the social utility dimension is high levels of perceived risktaking potential. The stereotype of a $\mathrm{CO}$ individual as a risk-taker helps $\mathrm{CO}$ individuals to be socially accepted for future professional relations (but not for future friendships). These findings emphasize the importance of considering both dimensions when investigating social judgments of $\mathrm{CO}$ and $\mathrm{CP}$. 


\section{General Conclusions}

The initial step in the present paper was to investigate and to explain the social judgments of different outlooks on the future. The literature previously showed that displays of CP are socially detrimental, whereas displays of CO are socially beneficial (Helweg-Larsen et al., 2002; Shepperd et al., 2005). These experiments have provided in-depth explanations of these results, taking the research one step further by demonstrating the importance of social dimension for judgments. $\mathrm{CP}$ is less socially rejected in the social desirability dimension than in the social utility dimension; therefore, a pessimistic bias may occasionally be less detrimental than expected (Helweg-Larsen et al., 2002), as it has a more negative effect in the professional than in the interpersonal domain. These conclusions are consistent with those of Furr and Funder (1998), who reported that unhappiness and non-clinical depression are considered contributing factors to maladaptive social interactions. Moreover, their results showed that social rejection of negative personalities is only observed in a few items from the NEO-PI relating to social utility; non-clinically depressed personalities are associated with low conscientiousness, low action and low openness. Additionally, both social judgment dimensions should be used to investigate the social drawbacks of $\mathrm{CO}$, as the dimensions are even more important when investigating the social benefits of $\mathrm{CO}$. It was previously shown that the social benefits of $\mathrm{CO}$ concern the social utility dimension, but not social desirability (Le Barbenchon \& Milhabet, 2005; Le Barbenchon et al., 2008). The current studies' results are consistent with previous results and clearly show that the benefits of $\mathrm{CO}$ for interpersonal relations only occur when $\mathrm{CO}$ is perceived as a positive illusion or as a manner of coping with a depressed mood. Thus, the social benefits of being optimistically biased may be fewer than expected (Shepperd et al., 2005; Taylor \& Brown, 1988) and mainly occur in the professional domain. These results are consistent with studies that report correlations between displays of optimism and advantageous self-descriptions by leaders (Dolbier et al. , 2001; Hickman et al., 
1996; House \& Shamir, 1998) and indicate that CO may be perceived as a sign of overconfidence and pretentiousness in interpersonal relationships (Taylor et al., 2003) or perhaps as self-absorption or insensitivity to social feedback (Colvin et al., 1995; John \& Robins, 1994).

The second step in the present paper was to investigate several possible reasons for the social judgments of outlooks on the future. The main factor taken into account in previous studies was the mood associated with particular outlooks (Carver et al., 1994; Helweg-Larsen et al., 2002). For this reason, the present study experimentally manipulated the presentations of the targets to convey "depressed" versus "non-depressed" moods. The results confirmed that our experimental manipulation was efficient. The results also showed that dysphoria mood is always attributed to individuals who display $\mathrm{CP}$, compared to individuals who display a neutral outlook or $\mathrm{CO}$, whatever the experimental condition. This stigma is so great that none of the three studies were able to overcome it.

Despite this stigma, the social rejection of depressed mood in the social desirability dimension was replicated; this effect is well established in the literature (Starr \& Davila, 2008). Indeed, as quoted by Helweg-Larsen "We might want to avoid associating with people who are sad, depressed and hopeless either because contact with such individuals is unpleasant or because they create a generally negative environment that most people prefer to avoid" (Helweg-Larsen et al., 2002, p. 104). Moreover, notable results were obtained concerning the role of depressed mood: 1) depressed mood is also rejected in the social utility dimension, and 2) the role of depressed mood in social rejection differs as a function of outlook on the future. This research showed that the social rejection of CP could be explained by the depressed mood that is attributed to it, as was observed by Helweg-Larsen et al. (2002). The current results show that this finding was mainly true for the social rejection of $\mathrm{CP}$ in the social desirability dimension. It is notable that the depressed mood attributed to the 
$\mathrm{CP}$ targets did not mediate their social rejection in the social utility dimension. In other words, the main social damage of CP (i.e., in the social utility dimension) cannot be explained by the depressed mood that is attributed to CP. Therefore, further studies are necessary to investigate the reasons behind the detrimental effects of $\mathrm{CP}$ in the social desirability dimension. In regards to $\mathrm{CO}$, if a depressed mood is associated with $\mathrm{CO}$, it might damage one's social perception in the professional domain, but depressed mood might also protect the individual from social rejection in the friendship domain. However, no obvious evidence was observed that the mood attributed to the CO targets explained how they were judged in the social desirability dimension when the participant had no additional information about the target (Study 3). Additionally, the non-depressed mood associated with CO did not explain its social acceptance in the social utility dimension.

Another explanation for the social judgments of $\mathrm{CO}$ individuals is that they are perceived as having the ability to take risks in social organizations. The highest levels of CO in the present study were associated with the greatest risk-taking potential, as was observed by Helweg-Larsen et al. (2002). Being a potential risk-taker would refer to having the potential to be innovative and the ability to forge ahead, regardless of the objective risks. In other words, the risk-taking potential attributed to the $\mathrm{CO}$ individuals may refer to their positive illusions, which assist them in forging ahead and taking initiative (Armor \& Taylor, 1998). This explanation is particularly suitable for the social acceptance of $\mathrm{CO}$ in the social utility dimension. This finding is in accordance with studies reporting that optimism enhances firm performance because it is associated with risky choices in professional domains (Anderson \& Galinsky, 2006). It is notable that perceived risk-taking potential does not influence social judgments regarding $\mathrm{CP}$ individuals; $\mathrm{CP}$ and $\mathrm{CO}$ may, therefore, be two different dimensions, rather than two extremes of a single "outlook on the future" continuum, as reported by Peeters, Czapinski, and Hoorens (2001). 


\section{Limitations}

In these studies, the profiles represented fictitious individuals, which is often the case for this type of paradigm. Helweg-Larsen et al. (2002) used hypothetical or recorded interviews. In future studies, it would be worthwhile to use such materials to reduce the artificiality of these profiles. An additional limitation concerns the plausibility of the targets. Do such targets really exist? Is it plausible to be pessimistic and not depressed? It is true that people who are in bad moods (Abele \& Hermer, 1993; Salovey \& Birmaum, 1989) or are anxious (Dewberry \& Richardson, 1990) or depressed (Alloy \& Ahrens, 1987; Pietromonaco \& Markus, 1985; Pyszczynski, Holt, \& Greenberg, 1987) display often lower comparative optimism than non-anxious, non-depressed, and happy people, but are not necessarily realistic or pessimistic (Helweg-Larsen \& Shepperd, 2001). Additionally, anxiety, bad mood and depression are not systematically congruent with pessimism. In this context, the plausibility of being pessimistic but not depressed appeared in study 2 by Helweg-Larsen et al. (2002), as well as in the current studies. In addition, is it plausible to be optimistic and depressed? In the same way, congruence between outlook on the future and mood is expected. Such targets were not tested in previous studies about social acceptance. However, all of these types of targets were perceived as credible in all studies. In this context, behavioral measures could be used to test acceptance and rejection. For example, a realistic encounter or a simulation of recruitment could be organized to increase the credibility of the situation.

Despite these limitations, the results support the idea that investigations of the social acceptance of $\mathrm{CP}$ or $\mathrm{CO}$ require consideration of both dimensions of social judgment because the depressed mood attributed to CP targets was not sufficient to justify their social rejection (which was mainly observed in the social utility dimension). The perceived potential for risktaking appears to be a promising avenue for exploring the social benefits of $\mathrm{CO}$ (which are only observed in the social utility dimension). 


\section{References}

Abele, A., \& Hermer, P. (1993). Mood influences on health-related judgments: Appraisal of own health versus appraisal of unhealthy behaviours. European Journal of Social Psychology, 23, 613-625. http://dx.doi.org/10.1002/ejsp.2420230606

Alloy, L. B., \& Ahrens, A. H. (1987). Depression and pessimism for the future: biased use of statistically relevant information in predictions for the self versus others. Journal of Personality and Social Psychology, 52, 366-378. http://dx.doi.org/10.1037//00223514.52.2.366

Alloy, L. B., Fedderly, S. S., Kennedy-Moore, E., \& Cohan, C. L. (1998). Dysphoria and social interaction: An integration of behavioral confirmation and interpersonal perspectives. Journal of Personality and Social Psychology, 74, 1566-1579. http://dx.doi.org/10.1037//0022-3514.74.6.1566

Anderson, C., \& Galinsky, A. D. (2006). Power, optimism, and risk-taking. European Journal of Social Psychology, 36, 511-536. http://dx.doi.org/10.1002/ejsp.324

Armor, D.-A., \& Taylor, S.-E. (1998). Situated optimism: Specific outcome expectancies and self-regulation. In M. P. Zanna (Ed.). Advances in experimental social psychology. (Vol. 30, pp. 309-379). San Diego, CA: Academic Press.

Bougheas, S. (2002). Optimism, education and industrial development. Research in Economics, 2, 199-214. http://dx.doi.org/10.1006/reec.2001.0276

Cambon, L. (2006). Désirabilité sociale et utilité sociale: Deux dimensions de la valeur communiquée par les adjectifs de personnalité [Social desirability and social utility: Two evaluative dimensions of Personality Traits]. Revue Internationale de Psychologie Sociale/International Review of Social Psychology, 19, 125-151.

Cambon, L., Djouary, A., \& Beauvois, J.L. (2006). Social judgment norms and social utility: When it is more valuable to be useful than desirable. Swiss Journal of 
Psychology, 65, 167-180. http://dx.doi.org/10.1024/1421-0185.65.3.167

Carver, C. S., Kus, L. A., \& Scheier, M. F. (1994). Effects of good versus bad mood and optimistic versus pessimistic outlook on social acceptance versus rejection. Journal of Social and Clinical Psychology, 13, 138-151. http://dx.doi.org/10.1521/jscp.1994.13.2.138

Chambers, J. R., \& Windschitl, P. D. (2004). Biases in social comparative judgments: The role of nonmotivated factors in above-average and comparative-optimism effects. Psychological Bulletin, 130, 813-838. http://dx.doi.org/10.1037/0033-2909.130.5.813

Colvin, C. R., Block, J., \& Funder, D. C. (1995). Overly positive self-evaluations and personality: Negative implications for mental health. Journal of Personality and Social Psychology, 68, 1152-1162. http://dx.doi.org/10.1037//0022-3514.68.6.1152

Dewberry, C., \& Richardson, S. (1990). Effect of anxiety on optimism. Journal of Social Psychology, 130, 731-738. http://dx.doi.org/10.1080/00224545.1990.9924625

Dolbier, C. L., Soderstron, M., \& Steinhardt, M. A. (2001). The relationships between selfleadership and enhanced psychological, health, and work outcomes. The Journal of Psychology, 135, 469-485. http://dx.doi.org/10.1080/00223980109603713

Dubois, N., \& Beauvois, J.-L. (2005). Normativeness and individualism. European Journal of Social Psychology, 35, 123-146. http://dx.doi.org/10.1002/ejsp.236

Dubois, N., \& Beauvois, J.-L. (2011). Are some rabbits more competent and warm than others? The lay epistemologist is interested in object value but not in descriptive parameters. Swiss Journal of Psychology, 70, 63-73. http://dx.doi.org/10.1024/1421$0185 / \mathrm{a} 000040$

Furr, R. M., \& Funder, D. C. (1998). A multi-modal analysis of personal negativity. Journal of Personality and Social Psychology, 74, 1580-1591. http://dx.doi.org/10.1037/00223514.74.6.1580 
Helson, H. (1964). Adaptation level theory. New York, NY: Harper \& Row.

Helweg-Larsen, M., \& Shepperd, J. A. (2001). Do moderators of the optimistic bias affect personal or target risk estimates? A review of the literature. Personality and Social Psychology Review, 5, 74-95. http://dx.doi.org/10.1207/S15327957PSPR0501_5

Helweg-Larsen, M., Sadeghian, P., \& Webb, M. S. (2002). The stigma of being pessimistically biased. Journal of Social and Clinical Psychology, 21, 92-107. http://dx.doi.org/10.1521/jscp.21.1.92.22405

Hickman, S. E., Watson, P. J., \& Morris, R. J. (1996). Optimism, pessimism, and the complexity of narcissism. Personality and Individual Differences, 20, 521-525. http://dx.doi.org/10.1016/0191-8869(95)00223-5

House, R. J., \& Shamir, B. (1998). Toward the integration of transformational, charismatic, and visionary theories. In M. Chemers \& R. Ayman (Eds.), Leadership theory and research: Perspectives and directions (pp. 81-107). San Diego, CA: Academic Press.

John, O. P., \& Robins, R. W. (1994). Accuracy and bias in self-perception: Individual differences in self-enhancement and the role of narcissism. Journal of Personality and Social Psychology, 66, 206-219. http://dx.doi.org/10.1037//0022-3514.66.1.206

Le Barbenchon, E., \& Milhabet, I. (2005). L’optimisme: Réponse désirable et/ou socialement utile? [Optimism: A desirable and/or socially useful response?]. Revue Internationale de Psychologie Sociale/International Review of Social Psychology, 18, 153-181.

Le Barbenchon, E., Milhabet, I., Steiner, D. D., \& Priolo, D. (2008). Social acceptance of exhibiting optimism. Current Research in Social Psychology, 14, 52-63.

Milhabet, I., Le Barbenchon, E., Molina, G., Cambon, L., \& Steiner, D. D. (2012). Comparative optimism, so useful. International Review of Social Psychology, 25, 540. 
Mussweiler, T. (2003). "Everything is relative": Comparison processes in social judgment. European Journal of Social Psychology, 33, 719-733. http://dx.doi.org/10.1002/ejsp.169

Nunnally, J. C., \& Bernstein, I. H. (1994). Psychometric theory ( $3^{\text {rd }}$ Ed). New York, NY: McGraw-Hill.

Peeters, G. (1971). The positive-negative asymmetry: on cognitive consistency and positivity bias. European Journal of Social Psychology, 1, 455-474. http://dx.doi.org/10.1002/ejsp.2420010405

Peeters, G. (2002). From good and bad to can and must: subjective necessity of acts associated with positively and negatively valued stimuli. European Journal of Social Psychology, 32, 125-136. http://dx.doi.org/10.1002/ejsp.70

Peeters, G., Czapinski, J., \& Hoorens, V. (2001). Comparative optimism, pessimism and realism with respect to adverse events and their relationship with will to live. International Review of Social Psychology, 14, 143-162.

Peretti-Watel, P. (2005). La culture du risque, ses marqueurs sociaux et ses paradoxes: Une exploration empirique (Risk culture, social bookmarking an dits paradoxes: An empirical exploration). Revue Économique 56, 371-392. http://dx.doi.org/10.3917/reco.562.0371

Pietromonaco, P. R., \& Markus, H. (1985). The nature of negative thoughts in depression. Journal of Personality and Social Psychology, 48, 799-807. http://dx.doi.org/10.1037//0022-3514.48.3.799

Preacher, K. J., \& Hayes, A. F. (2008). Asymptotic and resampling methods for estimating and comparing indirect effects. Behavior Research Methods, 40, 879-891. http://dx.doi.org/10.3758/BRM.40.3.879 
Pyszczynski, T., \& Greenberg, J. (1985). Depression and preference for self-focusing stimuli after success and failure. Journal of Personality and Social Psychology, 49, 10661075. http://dx.doi.org/10.1037//0022-3514.49.4.1066

Pyszczynski, T., \& Greenberg, J. (1986). Evidence for a depressive self-focusing style. Journal of Research in Personality, 20, 95-100. http://dx.doi.org/10.1016/00926566(86)90112-1

Pyszczynski, T., \& Greenberg, J. (1987). Self-regulatory perseveration and the depressive self-focusing style: A self-awareness theory of reactive depression. Psychological Bulletin, 102, 122-138. http://dx.doi.org/10.1037/0033-2909.102.1.122

Pyszczynski, T., Holt, K., \& Greenberg, J. (1987). Depression, self-focused attention, and expectancies for positive and negative future life events for self and others. Journal of Personality and Social Psychology, 52, 994-1001. http://dx.doi.org/10.1037//00223514.52.5.994

Quadrel, M. J., Fischhoff, B., \& Davis, W. (1993). Adolescent (in)vulnerability. American Psychologist, 48, 102-116. http://dx.doi.org/10.1037//0003-066X.48.2.102

Salovey, P., \& Birmaum, D. (1989). Influence of mood on health-relevant cognitions. Journal of Personality and Social Psychology, 57, 539-551. http://dx.doi.org/10.1037//00223514.57.3.539

Shepperd, J. A., Grace, J., Cole, L. J., \& Klein, C. (2005). Anxiety and outcome predictions. Personality and Social Psychology Bulletin, 31, 267-275. http://dx.doi.org//10.1177/0146167204271322

Siegel, S. J., \& Alloy, L. B. (1990). Interpersonal perceptions and consequences of depressive-significant other relationships: A naturalistic study of college roommates. Journal of Abnormal Psychology, 99, 361-373. http://dx.doi.org/10.1037//0021$843 X .99 .4 .361$ 
Spire, B., \& Peretti-Watel, P. (2008). Sida. Une maladie chronique passée au crible [AIDS. Chronic disease sifted]. Paris, France: Presses de l'EHESP.

Starr, L. R., \& Davila, J. (2008). Excessive reassurance seeking, depression, and interpersonal rejection: A meta-analytic review. Journal of Abnormal Psychology, 117, 762-775. http://dx.doi.org/10.1037/a0013866

Taylor, S. E., \& Brown, J. D. (1988). Illusion and well-being: A social psychological perspective on mental health. Psychological Bulletin, 103, 193-210. http://dx.doi.org/10.1037//0033-2909.103.2.193

Taylor, S. E., Lerner, J. S., Sherman, D. K., Sage, R. M., \& McDowell, N. K. (2003). Portrait of the self-enhancer: Well adjusted and well liked or maladjusted and friendless? Journal of Personality and Social Psychology, 84, 165-176. http://dx.doi.org/10.1037//0022-3514.84.1.165

Tice, D. M., Butler, J. L., Muraven, M. B., \& Stillwell, A. M. (1995). When modesty prevails: Differential favorability of self-presentation to friends and strangers. Journal of Personality and Social Psychology, 69, 1120-1138. http://dx.doi.org/10.1037//00223514.69.6.1120

Tyler, J. M., \& Rosier, J. G. (2009). Examining self-presentation as a motivational explanation for comparative optimism. Journal of Personality and Social Psychology, 97, 716-727. http://dx.doi.org/10.1037/a0016231

Ucbasaran, D., Westhead, P., Wright, M., \& Flores, M. (2010). The Nature of entrepreneurial experience, business failure and comparative optimism. Journal of Business Venturing, 25, 541-555. http://dx.doi.org/10.1016/j.jbusvent.2009.04.001

van der Velde, F. W., van der Pligt, J., \& Hooykaas, C. (1994). Perceiving AIDS-related risk: Accuracy as a function of differences in actual risk. Health Psychology, 13, 25-33. http://dx.doi.org/10.1037//0278-6133.13.1.25 
Vollmann, M., Renner, B., \& Weber, H. (2007). Optimism and social support: The providers' perspective. Journal of Positive Psychology, 2, 205-215. http://dx.doi.org/10.1080/17439760701409660

Weinstein, N. D. (1980). Unrealistic optimism about future life events. Journal of Personality and Social Psychology, 39, 806-820. http://dx.doi.org/10.1037//0022-3514.39.5.806

Weinstein, N. D., Marcus, S. E., \& Moser, R. P. (2005). Smokers' unrealistic optimism about their risk. Tobacco Control, 14, 55-59. http://dx.doi.org/10.1136/tc.2004.008375

Wojciszke, B., \& Abele, A. (2008). The primacy of communion over agency and its reversals in evaluations. European Journal of Social Psychology, 38, 1139-1147. http://dx.doi.org/10.1002/ejsp.549

Zuckerman, M. (1979). Sensation seeking: Beyond the optimal level of arousal. New York, NY: Erlbaum Hillsdale.

Zuckerman, M. (1990). The Psychophysiology of Sensation Seeking. Journal of Personality, 58, 313-345. http://dx.doi.org/10.1111/j.1467-6494.1990.tb00918.x 
Table 1. page 14

Mean Judgments of Targets' Social Acceptance on the Social Utility and Desirability Dimensions According to their Outlook in Study 1

\begin{tabular}{llll}
\hline Outlook & CP & Neutral & CO \\
\hline Desirability $(S D)$ & $3.35_{\mathrm{a}}(.92)$ & $4.19_{\mathrm{b}}(1.09)$ & $3.97_{\mathrm{b}}(1.09)$ \\
Utility $(S D)$ & $2.97_{\mathrm{c}}(.87)$ & $3.60_{\mathrm{a}}(1.18)$ & $4.12_{\mathrm{b}}(1.08)$
\end{tabular}

Note. A common letter indicates a lack of significant difference (line by line and column by column), $p<.05$ 
Table 2. page 14

Mean Judgments of Targets' Social Acceptance on the Social Utility and Desirability

Dimensions According to Their Presentation (Depressed vs. Control vs. Non-depressed) and Their Outlook on the Future (CP vs. Neutral vs. CO) in Study 1.

\begin{tabular}{llll}
\hline Target presentation & Target outlook & Desirability (SD) & Utility (SD) \\
\hline Control & CP & $3.35_{\mathrm{ad}}(.97)$ & $2.97_{\mathrm{d}}(.90)$ \\
& Neutral & $4.19_{\mathrm{b}}(.88)$ & $3.49_{\mathrm{ad}}(.85)$ \\
& $\mathrm{CO}$ & $4.23_{\mathrm{bc}}(.83)$ & $4.22_{\mathrm{ce}}(.96)$ \\
Non-depressed & $\mathrm{CP}$ & $3.56_{\mathrm{ac}}(1.31)$ & $2.80_{\mathrm{d}}(1.35)$ \\
& Neutral & $4.40_{\mathrm{b}}(.89)$ & $3.80_{\mathrm{a}}(.94)$ \\
& $\mathrm{CO}$ & $3.86_{\mathrm{bc}}(.99)$ & $4.37_{\mathrm{ae}}(.79)$ \\
& $\mathrm{CP}$ & $3.14_{\mathrm{ad}}(.86)$ & $3.12_{\mathrm{ad}}(1.13)$ \\
& Neutral & $3.98_{\mathrm{b}}(1.17)$ & $3.50_{\mathrm{ac}}(.97)$ \\
& $\mathrm{CO}$ & $3.78_{\mathrm{bc}}(1.33)$ & $3.78_{\mathrm{ce}}(1.38)$
\end{tabular}

Note. A common letter indicates a lack of significant difference (line by line and column by column), $p<.05$. Standard deviations shown in parentheses. 
Table 3. page 15

Mean ratings of Targets on the Social Utility and Desirability Traits According to their Outlook in Study 1

\begin{tabular}{llll}
\hline Outlook & CP & Neutral & CO \\
\hline Desirability $(S D)$ & $1.41_{\mathrm{a}}(1.85)$ & $1.99_{\mathrm{b}}(2.01)$ & $.90_{\mathrm{a}}(.89)$ \\
Utility $(S D)$ & $.00_{\mathrm{c}}(1.58)$ & $1.02_{\mathrm{d}}(1.80)$ & $1.89_{\mathrm{e}}(1.75)$
\end{tabular}

Note. A common letter indicates a lack of significant difference (line by line and column by column), $p<.05$. 
Table 4. page 20

Mean Risk-Taking Potential Ratings According to the Targets' Outlook on the Future in Study 2

\begin{tabular}{lccccc}
\hline \multicolumn{1}{c}{ Outlook } & High CP & CP & Neutral & CO & High CO \\
\hline Non-depressed & $3.07_{\mathrm{a}}$ & $4.10_{\mathrm{b}}$ & $3.08_{\mathrm{b}}$ & $4.95_{\mathrm{c}}$ & $5.19_{\mathrm{c}}$ \\
$S D$ & 1.24 & 1.16 & .72 & 1.05 & 1.25 \\
\hline Depressed & $2.83_{\mathrm{d}} *$ & $3.15_{\mathrm{d}} *$ & $4.02_{\mathrm{a}}$ & $4.97_{\mathrm{c}}$ & $5.09_{\mathrm{c}}$ \\
$S D$ & 1.46 & 1.37 & .71 & 1.28 & 1.28
\end{tabular}

Note. A common letter indicates a lack of significant difference (line by line and column by column), $p<.05 . * p=.058$. 
Table 5. page 21

Beta Coefficients of Multiple Regression Analyses for Comparatively Pessimistic or Optimistic Targets (not Neutral Targets) in Study 2

Social Desirability traits Social Utility traits

\section{CO targets}

Depressed mood

.06

$-.51 * *$

Risk-taking potential

.09

.03

CP targets

Depressed mood

$.16^{*}$

$-.07$

Risk-taking potential

$.24 * *$

$.24 * *$

Note. ${ }^{*} p<.05 .{ }^{* *} p<.001$. 
Table 6. page 25

Mean judgments of depressed mood attributed to the target according to Target's outlook on the future in Study 3

\begin{tabular}{cccccccccc}
\hline Outlook & CP4 & CP3 & CP2 & CP1 & neutral & CO1 & CO2 & CO3 & CO4 \\
& $-68 \%$ & $-52 \%$ & $-33 \%$ & $-17 \%$ & $+/-0 \%$ & $+17 \%$ & $+33 \%$ & $+52 \%$ & $+68 \%$ \\
\hline Means & $5.71_{\mathrm{a}}$ & $5.18_{\mathrm{b}}$ & $4.57_{\mathrm{c}}$ & $4.10_{\mathrm{d}}$ & $3.74_{\mathrm{e}}$ & $3.22_{\mathrm{e}}$ & $2.80_{\mathrm{f}}$ & $2.79_{\mathrm{f}}$ & $2.30_{\mathrm{g}}$ \\
$\mathrm{SD}$ & .94 & .99 & .83 & .81 & .96 & 1.08 & .81 & 1.22 & .70 \\
\hline
\end{tabular}

Note. A common letter indicates a lack of significant difference, $p<.05$ 
Table 7. page 25

Mean risk-taking potential attributed to the target according to Target's outlook on the future in Study 3

\begin{tabular}{cccccccccc}
\hline Outlook CP4 & CP3 & CP2 & CP1 & neutral & CO1 & CO2 & CO3 & CO4 \\
& $-68 \%$ & $-52 \%$ & $-33 \%$ & $-17 \%$ & $+/-0 \%$ & $+17 \%$ & $+33 \%$ & $+52 \%$ & $+68 \%$ \\
\hline Means & $2.85_{\mathrm{a}}$ & $3.10_{\mathrm{a}}$ & $3.77_{\mathrm{b}}$ & $3.82_{\mathrm{b}}$ & $4.24_{\mathrm{c}}$ & $4.33_{\mathrm{c}}$ & $4.80_{\mathrm{d}}$ & $4.99_{\mathrm{de}}$ & $5.15_{\mathrm{e}}$ \\
$\mathrm{SD}$ & 1.44 & 1.21 & 1.12 & .78 & .90 & 1.02 & 1.24 & 1.42 & 1.49 \\
\hline
\end{tabular}

Note. A common letter indicates a lack of significant difference, $p<.05$ 
Table 8. page 26

Mean Judgments of social acceptance on Social Utility and Desirability Dimensions Attributed to Target in accordance with Target's outlook on the future in Study 3

\begin{tabular}{|c|c|c|c|c|c|c|c|c|c|}
\hline Outlook & $\mathrm{CP} 4$ & $\mathrm{CP} 3$ & $\mathrm{CP} 2$ & $\mathrm{CP} 1$ & Neutral & $\mathrm{CO} 1$ & $\mathrm{CO} 2$ & $\mathrm{CO} 3$ & $\mathrm{CO} 4$ \\
\hline & $-68 \%$ & $-52 \%$ & $-33 \%$ & $-17 \%$ & $+/-0 \%$ & $+17 \%$ & $+33 \%$ & $+52 \%$ & $+68 \%$ \\
\hline Desirability & $2.41_{\mathrm{a}}$ & $2.91_{b}$ & $3.16_{b}$ & $3.72_{\mathrm{c}}$ & $5.22 \mathrm{~d}$ & $4.25_{f}$ & $4.39 \mathrm{fg}$ & $4.36_{f}$ & $4.07_{f}$ \\
\hline$S D$ & .81 & 1.04 & .84 & .78 & 1.01 & 1.10 & .89 & 1.21 & 1.21 \\
\hline Social utility & $2.02_{b}$ & $2.34_{\mathrm{a}}$ & $2.68_{c}$ & $3.33 \mathrm{~d}$ & $4.53 \mathrm{eg}$ & $4.04_{\mathrm{f}}$ & $4.43 \mathrm{~g}$ & $4.78_{\mathrm{e}}$ & $5.2_{\mathrm{h}}$ \\
\hline$S D$ & .78 & .85 & .65 & .74 & .90 & 1.05 & .97 & .97 & .98 \\
\hline
\end{tabular}

Note. A common letter indicates a lack of a significant difference (line by line and column by column), $p<.05$ 